\section{O Imaginário das Artes Plásticas: da representação \\ à simulação}

Nizia Villaça ${ }^{(1)}$

Resumo: Buscamos enfatizar, no artigo, a complexidade da questão do corpo, sua escolha e redefinição no campo das artes e seus limites. O desenvolvimento do biopoder com os estudos genéticos, a apologia do metacorpo protético ou do corpo virtual talvez remetam, também, ao desejo de superação da fragilidade da carne e da finitude. São, sobretudo, as manifestações artísticas contemporâneas que vão questionar e dinamizar as regras de proxemia e comportamento corporal, estimular novos contatos, novas posturas e uma nova liberdade, de inspiração natural, selvagem, infantil ou mesmo tecnológica, enfatizando a interação e questionando o controle.

Palavras chave: Corpo - Arte - Mídia - Biopoder - Comunicação - Simulação.

[Resumos em espanhol e inglês na página 274]

(1) Professora Titular Emérita da Escola de Comunicação/UFRJ, pós-doutorado em Antropologia Cultural, Paris V, Sorbonne. Pesquisadora 1 do CNPq, recebeu em 2009 a Bolsa Cientista do Nosso Estado - FAPERJ, Coordenadora do Grupo ETHOS: Comunicação, Comportamento e Estratégias Corporais, autora de livros e ensaios.

\title{
Introdução
}

Ó Deus estranho e misterioso, que só agora compreendo! Dai-me como vós tendes, o poder de criar corpos para as minhas almas. Ou levai-me deste mundo, que já estou exausto. Eu que fui feito à vossa imagem e semelhança. Amém! (Ismael Nery)

Quero romper com meu corpo, quero enfrentá-lo, acusá-lo, por abolir minha essência, mas ele sequer me escuta e vai pelo rumo oposto. (Carlos Drummond de Andrade)

Pessoas remendadas são experimentos pós- evolutivos.

(Stelarc) 
A pluralidade das vozes em epígrafe sugere o que está em questão: os limites do corpo, sua escolha e redefinição no campo das artes. Obviamente, encontraremos momentos de maior ou menor acordo com o que nos é simultaneamente presente e estranho, idêntico e diferente: o corpo, este complexo conglomerado biopsicossociológico. Usaremos como vetores de nossa reflexão a dinâmica identidade/alteridade e a oposição natureza/cultura. A propósito, cabe lembrar o pensamento de Henri-Pierre Jeudy (2002) sobre as operações da percepção. Segundo ele, operamos na arte ou no cotidiano uma reestruturação estética das imagens do corpo que surgem primeiramente como num sonho. Buscamos uma espécie de elaboração secundária, uma reconstrução do sonho em narrativa, reprimindo o estranho e a alteridade.

$\mathrm{Na}$ vida corrente, permanece o hábito de manter o corpo no claro/escuro da presença ausente. O desenvolvimento do biopoder com os estudos genéticos, a apologia do metacorpo protético ou do corpo virtual talvez remetam, também, ao desejo de superação da fragilidade da carne e da finitude (Slater, 1998, pp. 91-117). São, sobretudo, as manifestações artísticas contemporâneas que vão questionar e dinamizar as regras de proxemia e comportamento corporal, estimular novos contatos, novas posturas e uma nova liberdade, de inspiração natural, selvagem, infantil ou mesmo tecnológica, enfatizando a interação e questionando o controle.

A mídia celebra as megaexposições e as Bienais, os conceitos curatoriais, a arte eletrônica e as novas possibilidades de interatividade e imersão, ao mesmo tempo que discute a generalização do espetacular como recurso do mercado. Obviamente, a discussão recai sobre os pares arte/não arte, arte/moda (Oliveros, 2004, pp. 56-60), arte/vida (Fabbrini, 2001, p. 3), arte/tecnologia (Cypriano, 2004, p. E-6). As estéticas urbanas foram objeto de algumas das últimas Bienais, ou seja, a 25a (Iconografias metropolitanas) e a 27a (Como viver juntos), ambas com preocupações ligadas ao convívio social e ao programa ambiental, bem como a questão da política na arte, como vimos na 26a Bienal, intitulada Autonomia da arte. A pauta inclui a política das instituições que preferem, frequentemente, as apresentações de "risco zero" (Cypriano, 2001, p. E-1) dos já consagrados. Neste sentido, são importantes as mostras paralelas, abertura de novas galerias como a Vermelho em São Paulo. Sobre os semiestreantes, a curadora Daniela Bousso afirma: "Hoje não é mais preciso ficar martelando o trio Hélio Oiticica, Lygia Clark e Mira Schendel. Passamos 15 anos nisso. Queremos mostrar uma matéria viva, coisa que nosso mercado de arte ainda incipiente raramente considera" (Folha de S. Paulo, 2001, p. 15). Um dos expositores da galeria Vermelho declara que é nas situações menos valorizadas que se percebe tudo e trabalha em sua obra "O deslocamento do olhar", como afirma em entrevista na Folha de S. Paulo (Cypriano, 2004, p. E-4). A respeito da última Bienal, houve uma cadeia de loas à organização do evento que num clima de globalização trazia artistas para produzir suas obras in loco, mas a temática politicamente correta gerou também ataques: "O álibi das intenções éticas e intelectuais não consegue substituir o interesse da criação" (Coli, 2006, p. 2).

Daniela Labra (2006, pp. 12-13), na revista Número, ressalta que a "arte processual" de bases conceituais teria ainda hoje um efeito oxigenador das instituições de arte tal como ocorreu nas décadas de 60 e 70, tendo em seguida perdido o espírito reformulador inicial, adequando-se ao consumismo global e multiplicando os eventos de arte. Pergunta-se como podemos pensar o legado da arte processual no momento atual. Na mesma revista, 
Fernando Albuquerque (2006, pp. 14-15) sublinha a impossibilidade de fechar posições em torno das iniciativas mais recentes, catalogadas a partir de conceitos propostos pelos artistas segundo o tipo de dispositivo empregado (ação relacional, criação de território etc.), o equipamento utilizado (exposição, ação, performance etc.) e o corpo de informações ativado pelo projeto (artistas, curador, instituição etc.). No exemplo dado, "Arquivo de emergência", o que importa são as relações entre os diferentes agentes do circuito artístico e os projetos capazes de desnaturalizá-las, desestabilizá-las ou reprocessá-las.

A pequena transcrição de algumas provocações contemporâneas nos serve para introduzir a temática corporal, de seu momento da representação a tantas outras figurações, chegando às simulações e propostas em que o corpo efetivamente entra num infinito processo de produção.

\section{Corpo e Cultura: um trajeto antropológico}

O corpo constitui um subsistema cultural por meio do qual o indivíduo cria valores, coesão e interage com o mundo e com o outro. Os processos de subjetivação/dessubjetivação na contemporaneidade têm nele encontrado um locus onde as discussões se sucedem, seja num viés naturalista, colocando-o como baluarte da resistência aos processos de desmaterialização e metamorfose propiciados pela ciência e pela técnica, seja por meio de novos investimentos simbólicos que privilegiem sua desconstrução em campos de força, sua perda de organicidade. Em ambas as correntes, os limites são discutíveis, pois podem ir do neoludismo reacionário a um neoiluminismo tecnológico, com apostas no retorno à natureza e à corporeidade propriamente dita ou no acesso à progressiva perfeição de um metacorpo pós-orgânico e pós-humano.

A emancipação cultural do corpo é recente, embora este possua a idade de sua realidade biológica. O Ocidente, de um modo geral, avaliou-o a partir de preconceitos morais, estéticos, ideológicos e filosóficos, comprometendo o enunciado de sua natureza inapreensível. Para tal, contribuíram a condenação judaico-cristã da carne, a permanência do idealismo platônico e a rejeição da sensibilidade, em proveito das coisas do espírito. Sua emancipação é decorrência, segundo Paul Ardenne (2001), de três fatores: a investigação científica do corpo orgânico; o desvelamento psicológico da complexidade do pensamento sensível; a atenção sobre a mecânica dos afetos e a dessacralização da cultura a partir do Renascimento e, sobretudo, do Iluminismo. A arte, de alguma forma, indexou, na figura, a mutação dos saberes e dos pontos de vista. A liberação da forma acompanhou como um duplo simbólico a da matéria corporal.

A partir do final do século XIX, o corpo começa a assumir sua complexidade: sujeito e objeto; suporte do eu, mas também do outro; encarnação e também representação; carne e imagem. Nas palavras de Maria Rita Kehl, um corpo é

Um corpo e seu automóvel, um corpo e suas roupas, um corpo e seus remédios. E o Outro, e os outros que o rodeiam vivos ou mortos [...] Um corpo 
inclui o sentido e o sem sentido da vida e a dura noção da morte, que o acompanha deste a origem até ao final certeiro (Kehl, 2001).

Por tudo isso, nossos corpos nos pertencem menos do que acreditamos.

Michel Thevoz (1984) escreve belo livro de inspiração psicanalítica em que chama atenção para o fato de que o homem sempre teve relação problemática com a própria imagem, retocando o corpo de múltiplas maneiras: deformações, mutilações, tatuagens, escarificações, maquiagem, vestuário, cirurgia estética. Nascendo nu e desprotegido, exposto às intempéries e aos olhares, teve que se proteger de sua insignificância biológica e marcar a sua pertença à cultura e à comunidade. Assinala o autor a importância do corpo como suporte das marcas simbólicas na sociedade primitiva, anteriormente ao surgimento do Estado e do aparelho coercitivo exterior. Em tais sociedades, os indivíduos, por meio de pinturas corporais, fantasmavam os perigos inerentes ao mundo do informe para controlá-los. Daí as pinturas apelarem para o heterogêneo, para a alteridade. $\mathrm{O}$ primitivo incluía em sua pintura corporal aquilo que o ameaçava. Daí os traços fragmentados de suas representações que tanto nos angustiam. O homem não era concebido à imagem e semelhança de Deus. A pintura corporal contribuía para estabelecer ritualmente a comunicação com o além, facilitando a viagem iniciática, xamanística, ou seja, o devir inumano, animal etc. Esta necessidade era estrutural para a manutenção das comunidades.

$\mathrm{O}$ advento da escritura está ligado à construção dos estados e impérios e à hierarquização social. A lei do grupo cessa de ser figurada nos corpos, é transcrita sobre a pele anônima dos pergaminhos e tem a sua produção elitizada. A lei remete a um processo de desindividualização e universalização. Agora, marca-se o corpo para excluí-lo.

O quadro renascentista em suas diversas versões, como acentua Carlos Antônio Leite Brandão (2003), procurou definir o homem no mundo de forma diversa do período medieval, em que o corpo como índice do imutável se adaptava a grades e proporções figurativas e simbólicas, alegoria do divino e caminho da ordem terrena à ordem celeste. Com o Renascimento, inicia-se propriamente o espaço da representação do corpo individual e humano em versões que variam de autor para autor: Alberti e a metáfora do organismo, o homem inserido na história; Leonardo da Vinci, a fenomenologia do mundo e o homem natural; Michelangelo e o corpo complexo e relacional; o corpo da medicina de Vesálio. Com este último, começa a se forjar projeto de um corpo biônico. A analogia com a máquina vai permitir ao nosso espírito conviver com o corpo da representação e efetivar não mais a descrição escolástica ou a observação renascentista, mas um insaciável e moderno afã de domínio e artificialização. É esta visão cartesiana do corpo, expressa na perspectiva, que se dissemina a partir de então. É o corpo da lição de anatomia do Dr. Tulp (1632) de Rembrandt. O espaço da perspectiva, como o espaço cartesiano, constituiu reduções de nossa complexa experiência espacial. Esta abstração só foi possível pela transformação do espaço como dimensão corporalmente significativa, espaço fenomenológico, em espaço matemático estandartizado, possibilitando o surgimento de uma concepção mecânica do corpo. A esta técnica corresponderam uma abstração do corpo e uma ênfase de cunho racional na construção de seu sentido.

A revisão desta situação, dominante até o século XIX, é marcada pelo reconhecimento da corporalidade do sujeito. Perceber que nossa fisiologia, nossa experiência e nossa presença 
são cruciais em relação ao conhecimento tem como consequência a torção do espaço cognitivo. Rompe-se a perspectiva linear que o mantinha exterior e imóvel. Deste ponto de vista, o conhecimento implica interação, relação, transformação concomitante do sujeito e do objeto e questionamento da percepção.

A inclusão do corpo no processo artístico passa por vários estágios como a sensibilização do suporte, que perde a transparência, a preocupação com as marcas dos artistas que se deixam ver sob diversas formas, com a perda da terceira dimensão e outros processos que implicam a discussão da representação corporal.

O corpo e suas fronteiras com a matéria, a animalidade, o artifício, são extensamente trabalhados numa crise da visão antropocêntrica. Gestos, falas e imagens interrogam a unidade corporal, sua estabilidade, sua identidade por meio de analogias com o reino animal, fragmentações e deslocamentos inusitados. A prática da desconfiança contra a representação clássica da figura humana é sublinhada a partir do romantismo, com a temática do duplo, da sombra e do espectro para acessar progressivamente cenários de agressividade contra a representação do corpo belo, glorioso, sublimado.

\section{O Corpo em Dúvida, Feito em Pedaços}

O mal-estar da civilização esboçado por Freud encontra seu equivalente num desajuste do indivíduo consigo mesmo. Os heróis são agora vencidos e errantes. Sartrianos, como Roquentin em A náusea, ou Mateus, em Caminhos da liberdade, demonstram indecisão; em Camus, é o desespero. Embora haja uma multiplicação de tipos, podemos dizer que o século XX preferiu os anti-heróis. Picabia, dadaísta, em 1920, pinta um autorretrato intitulado Francis o fracassado; Egon Schiele pinta Nu masculino sentado: o corpo é descarnado e o pintor, esticado como um pano, não tem pés e os braços dissimulam a maior parte de seu rosto. Cresce a consciência assinalada por Deleuze e Guattari de que alguma coisa foge sempre. O impossível surge como desajuste entre o que o corpo deseja e aquilo que ele não pode (o entrave do princípio da realidade) com a entronização quase mecânica da frustração e do inacabamento existencial. O percurso da desfiguração das figuras humanas já era recorrente nas sombras fugidias da imaginação romântica expressando a inquietação em torno da questão da identidade. A aparição do duplo vem denunciar a ilusão das aparências e revelar o absurdo da suposta integridade do homem. O duplo principia o fim da estética da imitação (Moraes, 2002, p. 127). Sugestivo a este respeito é o conto de Hoffmann, O homem de areia, com a indistinção entre o humano e o autômato que parecem obedecer a um mesmo regime.

O passo seguinte é a aproximação do homem das formas animalescas. Os surrealistas verão na animalidade um estado original a ser reconquistado. Bataille, segundo Eliane Robert Moraes (2002, p. 127), sugere que sob a ótica selvagem o ser humano é um animal fechado numa prisão. A metamorfose representa, para o autor, uma condição atávica do homem, que, no limite, o impede de identificar-se ao ideal humano, lançando-o às necessidades animais. Michel Leiris, no artigo "Metamorfose", afirma deplorar os homens que não sonharam, pelo menos uma vez na vida, em se transformar em qualquer um dos 
objetos que o rodeiam: mesa, cadeira, animal, tronco de árvore, folha de papel... (Leiris, 1991). Um recurso usado é a máscara que destrói a normalidade humana. O antropomorfismo é lançado no jogo das metamorfoses, e a figura humana é reduzida ao estado de coisa. A obra de Hans Bellmer, com suas bonecas desarticuladas, sugere a violência nazista. As "máquinas celibatárias" de Duchamp decompõem a anatomia humana em vapores, faíscas ou ondas magnéticas, em mecanismos delirantes: La maricée mise à nu par ses célibataires, même. A leitura de tal mecanização e objetivação do corpo, segundo Eliane Robert Moraes, tanto pode ser vista numa linha frankfurtiana apontando a morte do corpo pela máquina, como, pelo contrário, ser um canto em louvor da inutilidade, da improdutividade e do lúdico.

As tendências vanguardistas do início do século vão sublinhar diversas vertentes que marcam a desconstrução da figura humana. O corpo se torna estranho para si mesmo, como na pintura de Giorgio de Chirico (pintura metafísica), que, de alguma forma, introduz o Surrealismo. O homem triunfante é substituído pela silhueta incerta, perdida na paisagem grande e incompreensível. Diz Breton no manifesto surrealista de 1924: "a imagem é uma criação pura do espírito, ela não pode nascer de uma comparação, mas da aproximação de duas realidades mais ou menos afastadas". É interessante introduzir aí a leitura que José Gil (1997) faz do corpo como significante flutuante, aquele que, não pertencendo a nenhum código simbólico, permite as correspondências, as metáforas e as metonímias das figurações na arte: "O significante flutuante designa esta força primária que, no mundo primitivo, circula por toda a parte entre os diversos mundos, atravessando os códigos, enchendo os seres e as coisas de poderes, de sorte e de vida" (Gil, 1997, p. 25). O corpo como experiência total, assunto de outro livro deste autor, enfatiza esta consciência corporal que de certa forma é uma consciência inconsciente e invade o pensamento racional, permitindo a percepção da alteridade que este normalmente procura censurar (Gil, 2001). Uma das maneiras artísticas de criar a dúvida sobre o homem é torcer sua aparência: o dadaísmo reivindica a banalização da feiura com as máscaras de Marcel Janco e a sistematização da fotomontagem com Hausmann que recorta sem piedade a unidade das figuras; os futuristas proclamam a violência como motor da representação; os expressionistas e os cubistas se servem de máscaras negras e polinésias para desintegrar a ordem repressiva. A morte da mimesis, que a deformação consagra, entre muitos exemplos pode ser vista em Les demoiselles d'Avignon (1907). O lento e paciente trabalho de desfiguração trata de forma africanizada as demoiselles do bordel de Barcelona, Calle de Avignon. Interessante, em contrapartida, a propósito da evolução da representação da figura humana na cultura africana do século XX, em exposição no CCBB, são exemplos de formalização abstrata com tendências cubistas. A versão antropológica de uma arte primitiva sem evolução é problematizada (Junge, 2003). Vale a palavra do Ministro Gil sobre o jeito da arte africana: "não é contemplativa, nem uma realização narcisista. Ela nunca foi apenas uma representação do mundo. Ela é, em todas as Áfricas, e também nas Áfricas de exílio, um instrumento de construção do mundo, um instrumento mágico" (Junge, 2003, p. 7). O corpo aparece aí como matéria de experiência, registro lúdico, uma das linhas da arte no século XX, paralela ao desconstrutivismo agressivo. 


\section{Carne e Imagem}

A representação corporal ocidental sofreu uma desagregação da instância unificada da pessoa humana com o retorno dos fantasmas do corpo fragmentado anterior à constituição do Eu. Impulsos primitivos e selvagens sempre ameaçaram o projeto antropocêntrico, criando descentramentos de nossa sensibilidade, notadamente, como tentamos apontar, a partir das vanguardas.

Posteriormente passou-se do questionamento da representação à problematização de nossa própria percepção. Uma das linhas assinaladas por Thevoz (1984) é o que ele chama de ressurreição da carne que implica a quebra da moldura e de seu efeito de realidade, a introdução da marca do autor, a sensibilização do suporte. O quadro ortogonal marcava a repressão da corporeidade do suporte e, correspondentemente, a do espectador. O funcionamento especular da imagem pressupunha a desencarnação do sujeito que a fundava. A ciência moderna, colocando em causa a objetividade e o determinismo dos processos naturais, desalojou o observador, que passa a fazer parte do sistema observado. Os artistas, como os cientistas, tomam consciência de sua inerência corporal e mental. Esta evolução é sensível na pintura, em particular a partir dos românticos, impressionistas e simbolistas que reativam os constituintes materiais do quadro: a tela, o grão, a camada pigmentar, o traço, o toque, são sensibilizados e solicitam uma apreensão epidérmica com o curtocircuito da distância descritiva. As imagens de David ou Ingres perdem em profundidade para coincidir com o plano do suporte, restituindo-lhe de certa forma seu valor tátil.

Thevoz fala do ressurgimento da pintura corporal no século XX como a volta do reprimido e refere-se a Viena como o lugar onde, sugestivamente, torna-se dramática a luta entre um formalismo tornado rígido e uma sensualidade verdadeiramente desordenada. $\mathrm{Na}$ arte, na literatura, como na psicanálise, sente-se o estremecimento vindo dos corpos, de suas pulsões, que deformam e deslocam as superestruturas. Hugo von Hofmannsthal fala de movimentos internos de suas entranhas, Gustav Klint, Egon Schiele e Paul Klee oferecem outros exemplos em que o corpo se mistura com a superfície do papel, ressaltando a sensibilização epidérmica do suporte "como o homem, o quadro é também o esqueleto, músculo e pele" (Klee, Apud, Thevoz, 1984, p. 103). É como se houvesse uma anatomia do quadro, como se o suporte readquirisse suas qualidades carnais que a tradição representativa secular havia subtraído. A imagem readquire o poder mágico depois de anos de despossessão antropocêntrica. Yves Klein, em suas Antropometrias, decalca corpos sobre papéis e telas (1960). Após os pincéis vivos deste autor, a pintura pop denuncia um corpo vampirizado por sua imagem. É a perda da identidade na estratificação da representação. A imagem precede o referente. Apesar de seu retorno aparente e, mesmo espetacular, à figuração, a pop art está em oposição à concepção do retrato glorioso dos pintores clássicos. Wilson Coutinho, entretanto, discorda da perda da aura da pop art americana e coloca em confronto Rubens Gerchman, em cuja obra as imagens urbanas kitsch são completamente diferentes das auráticas Marilyn Monroe de Andy Warhol nas quais o sistema hollywoodiano não consegue ser reduzido. Gerchman é o nosso pop da cidade moderna, alucinada e caótica, das misses patéticas em tempos da ditadura (Coutinho, 1989, p. 10-11).

A evolução da representação, de agora em diante, efetua uma espécie de reatualização dramática do estágio do espelho. Arnulf Rainer (Figura 1), vienense, fotografa suas próprias 


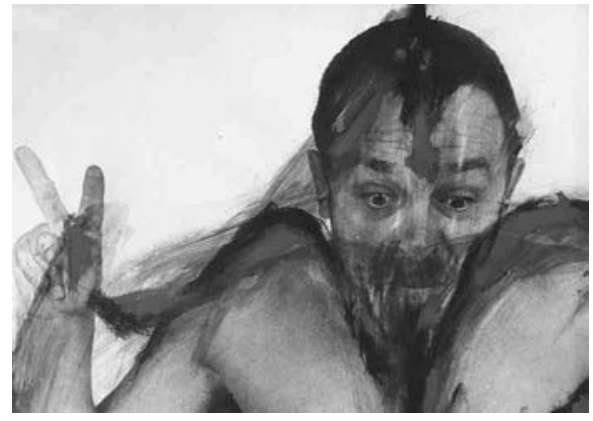

Figura 1. Hermannn

Nitsche In. https://

medium.com/@lidiazuin/ arnulf-rainer-hermannnitsch-e-gottfriedhelnwein-79a646256f30

gesticulações, caretas e contorções e intervém, em seguida, sobre a película, estabelecendo um jogo entre o corpo expressivo e a imagem de papel manchado. Há uma espécie de raiva impotente e secreta jubilação masoquista nesta aspiração de coincidência especular consigo mesmo. Uma tal ambiguidade caracteriza a body art. Piero Manzoni, em 1961, expõe na Galeria de Artes Moderna em Roma as esculturas vivas, modelos nus trazendo nos rins a assinatura do artista e apresentados sobre bases. Depois de séculos de mímesis, os ready mades humains. A body art, numa de suas versões interpretativas, radicaliza o espírito do happening, abolindo a distinção entre produtores e consumidores da arte. Os cerimoniais performáticos repetem os cerimoniais primitivos como farsa. A relação com o corpo é invertida: a marca que era aplicada ao corpo nu primitivo visava a arrancá-lo da natureza da animalidade e da insignificância para inseri-lo na ordem simbólica; na body art, ao contrário, a marca se aplica ao corpo glorioso do humanismo ocidental para profaná-lo, reagindo contra o consumo. Para os militantes da body art, o corpo representou o último reduto da experiência estética. Gina Pane, por exemplo, nos anos 70, marca ações próximas da náusea como comer quilos de carne picada, ferir-se etc., misturando o sangue com o leite. A arte da performance nos anos 60 restitui o corpo a si mesmo, é a arte como apropriação da carne, consciência de ser carne, antes de desenvolver seu trabalho com imagem que parece querer devorar o artista em Tropicália e outros trabalhos posteriores (Oiticica, 2003). Em 1969, Lygia Clark afirma a fase sensorial de seu trabalho, dizendo mesmo haver incorporado o objeto, tornando-se objeto de sua própria sensação (Clark, 1980). No universo da experiência corporal, sem dúvida alguma, Lygia Clark e Hélio Oiticica ocupam um lugar exponencial que vem sendo sempre mais explorado pela nova crítica como referência da arte na sensibilização e vibração corporal.

Nos primeiros anos da década de 1970, muitos "bodystas" como Jonas, Acconci e Bruce Nauman deslocam inteiramente para o vídeo e para os seus videoteipes as suas operações corporais e dão início àquela que pode ser considerada a tendência maior e mais praticada da videoarte dos anos 70. Para Mário Costa (1990), nesta exploração tecnológica do corpo, a body art tira a máscara e aparece a um tempo como lamento fúnebre sobre a carne 


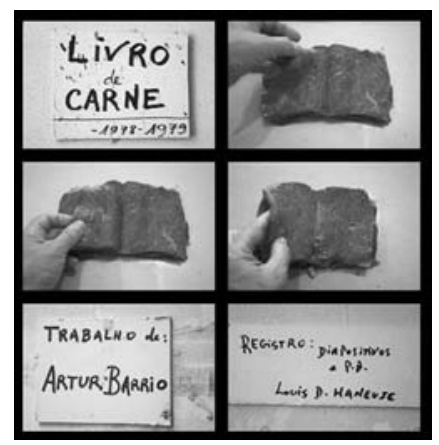

Figura 2: Livro de Carne. Arthur Barrio. (1977-1978). In https://www.publico. $\mathrm{pt} / 2017 / 02 / 12 /$

que morre e como anúncio de toda uma nova época do corpo: o fim último da body, a sua meta inconsciente, é a espetacularização do corpo, a sua transferência para novas mídias, a sua transformação em uma mera memória de máquina.

O travestismo, por outro lado, acentua o lado máscara da pessoa e aponta para o desenvolvimento da arte ocidental a partir dos anos 70 no sentido da discussão corpo/imagem, utilizando, para tanto, a exploração e a mistura de diferentes suportes (vídeo, fotografia, recortes etc.). A arte conceitual dos anos 70 sublinha a abertura da representação, indo do pensamento puro à fisicalidade. Arte é processo, e a desmaterialização busca novas formas de expressão, subvertendo os sentidos humanos e derrubando valores que isolavam a experiência da vida. Embora no âmbito mundial tenha havido um caminho em direção à desmaterialização da arte é importante lembrar que no Brasil, portanto, a sensorialidade nunca chega a ser alienada. No fim da década de 60 , as experiências de artistas como Lygia Pape, Hélio Oiticica e Lygia Clark privilegiam o corpo, a sensação e a participação do espectador. Mais tarde, a obra de Arthur Barrio (Figura 2), muitas vezes feita de carne e restos; as instalações sensoriais de Cildo Meireles, que apelam para o olfato, o tato e o paladar do público; e a escultura extremamente expressiva e violenta de Ivens Machado serão exemplos de como as impressões do corpo ainda são importantes (Name, Apud, Costa, 2004, p. 15).

Os anos 80, embora lembrados pela recuperação das tintas e pincéis, não se resumem a esta visão, já que muitos destes jovens artistas não usaram apenas as formas usuais de pintar, criando uma obra híbrida, que reinventou suportes e materiais de impressão e flertou com o objeto e a tridimensionalidade. Segundo Daniela Name, o corpo é reafirmado como personagem e motor da obra e lembrado como pele, ossos e entranhas e transforma-se em elo ao unir os artistas da época. Ele é personagem de narrativas pop, ele expressa a subjetividade, é corpo-paisagem quase sempre aos pedaços, surge em suporte diferente da tela sobre o chassi, como demonstram Leonilson, Leda Catunda, Flemming e Romagnolo. O grande painel desta geração aconteceu na mostra "Onde está você, Geração 80?”. 


\section{Corpo, Devir e Projeto: heterogênese ou neoiluminismo tecnológico?}

... Nunca seria aceitável uma teoria ou sistema que, de algum modo, implicasse o sacrifício da experiência passional.

(Oscar Wilde)

Nietzsche, Freud e Deleuze, sequencialmente e de formas diferentes, redescreveram o corpo como uma superfície que reflete as características peculiares da vida moderna, o corpo tornado idêntico a sua imagem vivida. Constrói-se uma estética da existência, um corpo comunicativo na linha de Foucault. Se a "coisa em si" é banida como ilusão metafísica, então não se pode falar de aparências versus essência. Ambas são abandonadas em favor da vida como fenômeno em constante devir. As energias da vida atravessam o corpo humano deixando rastros enigmáticos. Para Paul Schilder (Apud, Ferguson, 1997, pp. 01-29), a "solidez" do corpo depende da contínua construção e reconstrução de sua imagem e de uma multiplicidade de perspectivas. Ele vê a fragmentação do clássico ego burguês como precondição para uma experiência mais substancial do corpo. A dissolução do ego não resulta na perda do corpo, mas numa reapropriação. De certa forma, ele remete a aspectos do "corpo sem órgãos" de Deleuze e Guattari. Para estes autores, o CsO é o que resta quando nos desligamos dos fantasmas, significâncias e subjetivações. Contra as estratificações, eles traçam um plano de consistência do desejo por agenciamentos diversos: perversos, artísticos, científicos, místicos, políticos, que forçosamente se cruzam. O inimigo do CsO não é o órgão, mas o organismo como um extrato sobre o $\mathrm{CsO}$, quer dizer, um fenômeno de acumulação e coagulação, sedimentação que lhe impõe formas, funções, ligações, organizações dominantes e hierarquizadas, para extrair o trabalho útil (Deleuze y Guattari, 1993, pp. 25-26). Neste sentido, Deleuze e grandes gurus do imaginário do corpo maquínico como Pierre Lévy e Joël de Rosnay pensam as novas experiências tecnológicas como enriquecimento dos processos de subjetivação e linhas de fuga. O corpo é ressignificado como intensidade e sua percepção é complexificada.

O limite entre a desconstrução como apropriação e a desconstrução como tática de alienação é uma preocupação atual da ética. O foco da reflexão são as estratégias do capitalismo financeiro globalizado e do complexo biotecnológico produtor e manipulador da vida no planeta buscando explorar os valores conquistados pelos movimentos sociais: liberdade corporal, flexibilidade, fluidez, ousadia, ultrapassagem de fronteiras culturais e biológicas e superação de limites. O retorno das filosofias morais e a preocupação com a ética, segundo Denise Benuzzi de Sant'Anna, buscam discernir os momentos em que "no lugar da diferença é valorizada a variação, em que, em vez da expressão corporal, adota-se o imperativo da boa forma e em que, no lugar da manifestação do desejo nômade, são legitimados os prazeres polivalentes e mutáveis" (Sant'Anna, 2001, p. 90).

As intenções de quebra do especular, nas "performances" e "instalações" do contemporâneo, para a afirmação de um corpo "primário", não resistem à leitura crítica de HenriPierre Jeudy. A aventura de quebrar o espelho e passar para o outro lado seria o grande estereótipo da exibição do corpo nestes eventos. Se a ideologia da liberação do corpo dos 
anos 60 e 70 é significativa da revolta contra a autoridade das representações e suas referências morais, hoje passa-se da dinâmica da liberação à “pressão da liberação", e o estético subsiste na forma de intelectualização que precede a própria performance, retirando-lhe a tensão entre representação e realidade.

Para o autor, a aventura do corpo exibido na performance é a da exacerbação dos estereótipos da representação corporal, ao passo que ela queria ser um aprofundamento do próprio processo de representação. Os discursos dos críticos de arte, apoiando-se nos sistemas teóricos das ciências sociais, nas construções filosóficas, utilizando a aparelhagem conceitual da psicanálise, ofereceriam uma variedade de pontos de vista. Em meio ao exibicionismo das metalinguagens, cria-se a feira de estereótipos. Deixa de haver a tensão entre imagem e representação e impõe-se um enquadramento de conceituação anterior às imagens do corpo. A arte torna-se verdadeira máquina de produzir a estereotipia cultural como um viveiro que engendra equivalência e banalidade. Não é esse aspecto de soberania que um bom número de artistas tenta alardear? - pergunta o autor. À conquista desenfreada da singularidade, que foi a finalidade implícita da criação artística no século XX, sucede o jogo doravante obrigatório com os estereótipos da singularidade. O corpo, mantendo-se a fonte sagrada de todas as ilusões, garante o futuro dos estereótipos. O corpo enigma permanece o grande estereótipo.

Na dramatização dos embates deste corpo que vê e é visto, que é sujeito e que é objeto, chegamos à cena do corpo virtual. O corpo torna-se incorporal? Torna-se autônomo e imortal nas imagens digitais para além das distinções entre o existente e o inexistente? Segundo ainda Henri-Pierre, o corpo puro do mundo virtual é o espelho do corpo perfeito em um mundo orgânico. A visão estética do mundo, apoiada no idealismo da corporeidade, acaba por integrar tudo que lhe resiste. O materialismo radical, utilizado por Henri-Pierre, funciona como excitação "intelectual” e ameaça ao idealismo estético. Questiona a revolução tecnológica, cuja aventura permitirá, talvez, a democratização da idealização do corpo e a circulação das imagens corporais.

A arte seguiu, no que concerne ao corpo, um caminho bastante complexo, impossível de se resumir. Tentamos apenas tematizar alguns aspectos que apontam para um projeto antropológico de cunho iluminista e, por outro lado, para a liberação de uma cultura instintual e ainda uma leitura que contemple o corpo como parte integrante do processo comunicativo, como acentua André Lemos (2002) em seus comentários sobre arte e novas tecnologias, em que passamos da representação à simulação. Com a digitalização do mundo, a imagem age como modelo dinâmico de construção de conhecimento sobre o real, com simulacros concebidos sob a forma numérica. Afirma ainda que a arte eletrônica é fruto, também, do processo de desconstrução dos metadiscursos que legitimaram a modernidade. Ela é coerente com a desconstrução, a virtualização e a desmaterialização do mundo pela qual estamos passando com o desenvolvimento da cibercultura, incluindo aí a figura do cyborg, a fusão do corpo biológico com as nanotecnologias inteligentes e implantes os mais diversos (Lemos, 2002, p. 198).

Desenvolve-se o que os curadores Ricardo Barreto e Paula Perissinoto, do "File" de 2002, no Paço das Artes, São Paulo, chamam de cultura da imanência nas redes virtuais, embora, segundo eles, é preciso cuidado para manter o jogo livre das performances, libertando-se das instituições transcendentes que buscam etiquetar os saberes, daí não se pode falar 
em arte digital, pois seria contraditório com o anárquico pluralismo de uma estética maquínica generalizada. O importante é que a performance esteja passando pelas redes não lineares e que vá das redes digitais às redes sinápticas e vice-versa. O hipertexto tem a ver com gatilhos e performances que acabam conectando todas as mídias numa hipermáquina digital, produção cultural compartilhada.

Não se trata mais da arte do suporte, ligada à materialidade, mas de criações que privilegiam o processo, como um evento a ser vivido. São modalidades de arte marcadas pela ideia de fluxo e de acontecimentos para o corpo conectado a ambientes virtuais. Toda arte interativa é regida por computadores que, na qualidade de tecnologia numérica, abrem o acesso aos dados guardados nas memórias invisíveis de redes de silício. Por outro lado, são as interfaces que nos conectam e permitem enviar os dados, ou seja, são os dispositivos de hardware que levam os inputs, colocando os dados para dentro do computador. A partir das conexões, os processos de captura, processamento e comunicação de sinais propiciam experiências estéticas expandidas pelas tecnologias (Domingues, Apud, Barros y Santaella, 2002, p. 60).

José Bragança de Miranda (Apud, Gianetti, 1998), de sua parte, a propósito da interatividade, faz crítica da nova mimese tecnológica e enfatiza o casamento da arte com a técnica, depois de haver flertado com o poder medieval e com o dinheiro. Partindo de Walter Benjamin, ele põe em foco o fato de que a técnica vai instaurar uma nova ilusão estética. De fato, depois de destruídas todas as categorias idealistas, a arte aparece confrontada com uma categoria universal: a da interatividade. Instala-se uma nova mimese tecnológica que, em conluio com a arte, procura determinar a forma do mundo. Segundo o autor, as artes interativas dão sequência ao vanguardismo, mas um vanguardismo em que a força do negativo se esgotou. As artes interativas têm em comum com as vanguardas a tendência a visar esteticamente o mundo, a produzi-lo tecnicamente. A negatividade desaparece numa positividade feliz que derruba todas as fronteiras. Duchamp, que tanto fez para desestetizar a arte, encontrar outra relação entre os objetos e a arte, é eleito o inspirador da arte tecnológica. Agora é a vida que entra na arte por meio de uma técnica capaz de afetar a totalidade do mundo e não a arte na vida. Construir a arte é construir a realidade, para Roy Ascott (1998).

O problema da mimese tecnológica é que impõe uma figura neutra que é a da interatividade como categoria técnica que metaforiza o feedback. Pretende ser apresentação automática e imediata. Segundo José Bragança, a arte não tem diretamente a ver com o mundo, preenche-o de objetos que dão visibilidade ao invisível, mas também o destrói ao fazer dele matéria para o seu exercício. A arte tecnológica nas suas diversas variantes está colocada no horizonte da categoria de interatividade, da qual dependem outras como conectividade, emergência, interfaces, simulação, inteligência artificial, hipertexto ou hipermídia, tempo real, virtual, instantaneidade, todas elas afetando profundamente o imaginário corporal que abandona o contato direto pela mediação (Thompson, 1999, s/p, en Barros y Santaella, 2002, pp.59-81).

No campo computacional, a tendência para criar sensores e descodificadores da percepção humana, de que depende a "apresentação" imediata em tempo real das artes tecnológicas, só é perigosa porque alimenta o imaginário de uma reconstrução "pós-biológica" do humano. Como se o humano fosse igual ao "corpo". Mas essa é a base da biocomputação, das 
nanotecnologias, em suma, do programa de desenvolvimento do cyborg, afirma ainda José Bragança de Miranda.

Um pouco por todo lado, vai-se sustentando que as instalações interativas introduzem experiência multissensorial no campo da arte... Os procedimentos operatórios interativos e a experimentação de interfaces fornecem a possibilidade de repensar as relações específicas entre órgãos dos sentidos, redistribuindo as suas funções (Ascott, 1995), sendo indiferente que o código se expresse através do som ou da fala, da visão ou do tato, e mesmo por sentidos menos trabalháveis, ainda, como o "sabor". O problema não está aí, mas no fato de que a definição da arte como "resposta em tempo real" a inputs que, vindos do corpo, ou do aparelho/programa, é similar (dada a desaparição tendencial da exterioridade). O tempo real é, afinal, a replicação mimética dos limiares percepcionais dos humanos, mas, acima de tudo, o rebatimento sobre o espaço de controle de todos os atos, nomeadamente os estéticos. De toda a maneira, a replicação sensorial, o bloco de sentidos biológicos-sensores técnicos implicam ainda uma distância, que se procura reduzir para finalmente anular. O paradigma atual deste processo é a tecnologia da "realidade virtual". O caso agrava-se com a "reconstrução pós-orgânica" do humano, mas não muda de figura. Mas o que está em causa é que a arte seja visualização, idêntica aos limiares percepcionais, quando ela é visibilidade determinada pela invisibilidade, luz determinada pela escuridão, presença determinada pela ausência.

Bastante diverso é o pensamento de Diana Domingues quando fala da ciberarte e da interatividade e incensa a capacidade do ciberespaço no sentido de provocar o campo da percepção. Se José Bragança de Miranda fala dos limites do corpo, da política e da transcendência da visão artística não aprisionada pela técnica, Diana aponta para uma espécie de além-mundo oferecido pela mescla de real e virtual. Segue aí a trilha de Mário Costa quando fala do sublime tecnológico. Mudez e deslumbramento. O conceito de interface se dá justamente na fronteira de corpos diferentes: o biológico e o sintético das máquinas. A obra é processo e não mais objeto na era pós-biológica. O corpo acoplado pode ser relacionado ao sujeito interfaceado de Edmond Couchot, nos seus estudos sobre a passagem do ótico ao numérico, apontando o desejo do homem de acoplar o corpo na produção da arte, como vimos no trajeto por nós descrito no item anterior com referência à body art, aos happennings, Pollock, Ives Klein. A interatividade para Diana é, sobretudo, oportunidade de fazer emergir simulacros de pensamento e de vir a ser. Parece-me que seu corpo interfaceado fala mais do desenvolvimento da ciência do que da arte.

A questão complexa da relação arte/tecnologia é muito discutida por autores contemporâneos entre os quais estaria Diana Domingues e a discussão radical da humanização das artes no século XXI; Lúcia Santaella com a análise semiológica e crítica da última produção na arte eletrônica; Arlindo Machado, com descrições técnicas e discussões políticas sobre a revolução biolítica em que as tarefas serão o domínio de nosso próprio corpo e dos organismos vivos em geral (Domingues, 1997, s/p, en Santaella, Noth y Machado, 2001). O artista contemporâneo deve efetivamente mexer com a caixa-preta do computador para produzir arte? Virou um produtor de efeitos especiais, ou cabe-lhe um papel crítico e negativo usando a própria técnica? Como fica o futuro do corpo humano entre a biosfera e a tecnosfera? A realidade cyborg constitui uma nova antropologia ${ }^{1}$ ? 

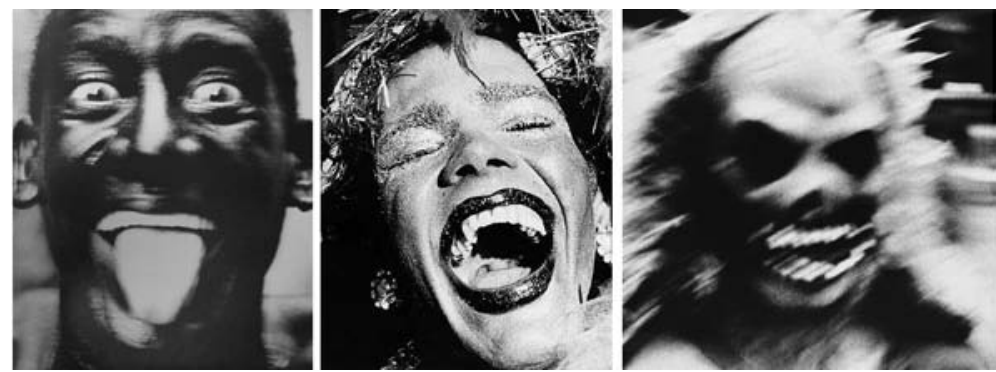

Figura 3. Arthur Omar. In http://www.usp.br/jorusp/arquivo/2004/jusp679/pag13.htm

É interessante lembrar aqui a obra de Arthur Omar (Figura 3), que transforma o ato fotográfico em ato dramático na sua obra Antropologia da face gloriosa. A pele e a tela se indiferenciam: "As imagens de Arthur Omar têm uma indecência material e simbólica; flamejam formas, latejam conteúdos [...]. Trata-se ainda de construir, na comunicabilidade imediata e empática da fotografia, os mesmos ritmos orgânicos e emocionais da vida" (CanongiaA, Apud y Omar, 1999).

No campo da arte, por exemplo, a partir sobretudo das décadas de 60 e 70, acentua-se o desmonte do pensamento polarizado, que começara ainda na segunda metade do século XIX, aumenta o trabalho de desconstrução do sujeito como fundamento e cresce a interação com a obra, ou seja, a colaboração do público participante no processo comunicativo que a obra instaura. Experiências de Lygia Clark, Lygia Pape e Hélio Oiticica foram determinantes. O importante era mobilizar a escala sensorial no subjetivismo renovado, e, como dizia Hélio, procurar pela descentralização da arte, pelo deslocamento do que se designa como arte. Passar do campo intelectual racional para o da proposição criativa vivencial (Medeiros, 2003, p. 153).

A exposição "Cosmococa", apresentada no momento no Centro Cultural Hélio Oiticica e apoiada em notas do artista em colaboração com Neville d'Almeida, dá a medida de seu pensamento revolucionário. A montagem está completamente em sintonia com o pensamento contemporâneo expresso em performances, instalações e vídeos.

A concepção da telepresença da realidade virtual tem profundas raízes na histórica intelectual: a automação e a busca da inteligência artificial, a ilusão na arte e a rejeição do corpo em favor de uma concepção espiritual e mentalista do eu humano. Segundo Oliver Grau (Apud, Bentes, 2005, pp. 112-117), a história da tecnologia sempre incluiu a história de suas utopias e mitos que revelam desejos humanos, impulsionando a história. Já na Antiguidade, foi concebido o modelo pneumático do homem, e o teatro mecânico de Heron automatizava a arte, e em Florença, no século XIV, Brunelleschi desenhou um palco mecânico para dar vida ao Paraíso. Se na Idade Média a visão mecanicista não encontrou ambiência, no século XVII encontramos analogias entre o corpo e a tecnologia mais ela- 
borada da época: o relógio. Decartes interpretava processos biológicos como ocorrências mecânicas, e Hobbes via, nos fenômenos mentais, corpos físicos em movimento. No século XVIII, o andróide chega à maturidade com o homem-máquina de La Mettrie. Com a obra de Hoffmann e Mary Shelley, imaginário que hoje reemerge na tentativa de produzir inteligência artificial na internet.

A arte virtual contemporânea encontra na história da arte toda uma tradição, e uma das mais famosas foi a instalação virtual do Sacro Monte, o Calvário (1518-22), cujo poder de fusão ilusória do afresco como primeiro plano envolvia os observadores com imagens fortes, havia mesmo visitas às capelas. Nos períodos Maneirista e Barroco, ainda segundo Oliver Grau, floresceram os panoramas, patenteados em $1787^{2}$. Tais instalações e a ilusão provocada poderiam, segundo alguns, até afetar a capacidade das pessoas em perceber a realidade. Numa época em que o turismo iniciava, os panoramas por vezes eram substitutos da presença física no estrangeiro. Havia os que preferiam à segunda.

A tendência ao ilusionismo forneceu motivação para os avanços da mídia no sentido da imersão e dos aparelhos diretamente diante dos olhos. Nos anos 30, a noção de telecomunicação tinha se fundido com a noção de vida artificial para formar uma visão de um ser humano descorporificado. A questão é que, na base deste desprestígio do corpo, estão inúmeras crenças que se travestem de cientificidade. Fica a questão para a mídia contemporânea considerar: se a realidade virtual, terminando com a distância, dificulta a reflexão e a localização física com a experiência visual e tátil oferecida quando se queira, em qualquer lugar e a qualquer momento, como havia predito Valéry. Através de redes conectando um número variável de tecnocorpos, a telepresença desdobra uma multiplicação possível de espaços de experiências e corpos.

O sentido da arte e da vida se funde, e a tecnologia como pensamento se coloca a serviço de uma percepção propriamente mística como acentua Arthur Omar (Apud, Ivana, 2005, pp. 17-23), citando o mestre sufi Rumi do século XIII. Em depoimento sobre a instalação Dervix, com material filmado em favela de Cabul, Arthur Omar sublinha a sua estranheza diante da experiência daqueles homens e de seu aparato tecnomental interior "talvez infinitamente mais sofisticado do que nossas tentativas para chamar as novas tecnologias de imersão". A instalação, no caso, propõe-lhe um trabalho de des-imersão que aponta para a luta entre duas propostas de transformação e expansão daquilo que chamamos de realidade.

O corpo e sua representação, simulação, virtualização se inscreve como o lugar onde infinitas apostas de recriação continuarão a se realizar.

Transcrevemos aqui trecho do conto "www.joy\&peacefuneraldesign.com", de Jair Ferreira dos Santos, em Cybersenzala:

Bem-vindo ao nosso site. Somos um ponto de mutação [...]. A J\&P oferece às famílias, amigos e admiradores de um ente querido que se foi um novo conceito - "hype", transfigurador- em funerais [...]. A J\&P disponibiliza nas grandes capitais do país uma extensa gama de serviços e produtos funerários -perto de 600 itens-com um único objetivo: poupar aos familiares o penoso estresse que envolvem os enterros, livrando-os ao mesmo tempo da burocracia da transição [...] (Santos, 2006, pp. 155-157). 
A provocação acima nos ajuda a pensar o processo de conexão e desconexão homem/máquina, suas sensações, seus devires e também a efetiva realização do paradigma anunciado do pós-humano, com a superação das antigas dicotomias disciplinares que ironicamente teimam em distinguir mídia e novas mídias, sendo as segundas igualadas à própria vida. Termino com uma lembrança de Guimarães Rosa comentando que a espécie humana peleja para impor ao latejante mundo um pouco de rotina e lógica, mas algo ou alguém de tudo faz zombaria.

\section{Notas}

1. Não podemos deixar de lembrar a relevância do trabalho de tantos outros estudiosos como André Lemos, Alex Primo, Erick Felinto, que pesquisam os novos vínculos e processos identitários, as interfaces dos espaços reais e virtuais.

2. Enormes telas foto-realistas -circulares, penduradas, geralmente com mais de 7.000 pés quadrados- envolviam hermeticamente os observadores. O objetivo central era transportar o observador para dentro da imagem, de modo que a pintura não mais fosse percebida como pintura.

\section{Referências Bibliográficas}

Albuquerque, F. (2006). “Sobre arquivos vivos e outras emergências". Número, n 9, dezembro de 2006. pp. 14-15.

Ardene, P. (2001). L'image corps: figures de l'humain dans l'art du 20e siècle. Paris: Regard.

Ascott, R. (1998). “A arquitetura de cibercepção”. In: GIANNETTI, Cláudia. Ars Telemática: telecomunicação, internet e ciberespaço. Lisboa: Relógio D’Água.

Canongia, L. (1999). "Antropologia extática”. In: OMAR, Arthur. O zen e a arte gloriosa da fotografia. Catálogo da exposição Antropologia da face gloriosa. Rio de Janeiro: CCBB.

Clark, L. (1980). Lygia Clark. Textos de Lygia Clark, Ferreira Gullar e Mário Pedrosa. Rio de Janeiro: FUNARTE (Arte brasileira contemporânea).

Coli, J. (2006). “A vanguarda do tédio". Folha de S. Paulo, Mais, nº 766, 19 de novembro de 2006. p. 2.

Costa, M. (1990). L'estetica dei media. Tecnologie e produzione artística. Lecce: Capone Editore.

Coutinho, W. (1989). Rubens Gerchaman. Produção e coordenação de Paulo Fernandes. Rio de Janeiro: Salamandra, 1989. p. 10-11.

Cypriano, F. (2004a). "Decepção artificial”. Folha de S. Paulo, Ilustrada, 14 de agosto de 2004. p. E-6.

. (2004b). "Obras provocam 'deslocamento do olhar'”. Folha de S. Paulo, Ilustrada, 10 de agosto de 2004. p. E-4. 
.(2001). "Artes plásticas nos tempos do neoliberalismo". Folha de S. Paulo, Ilustrada, 4 de setembro de 2001. p. E-1.

Deleuze, G. y Guattari, F. (1993). Mil platôs; capitalismo e esquizofrenia. v. 3. Rio de Janeiro: Ed. 34, 1993.

Domingues, D. (1997). A arte no século XXI: a humanização das tecnologias. São Paulo: Fundação Editora da UNESP.

. (2002). "Desafios da ciberarte: corpo acoplado e sentir ampliado". In: Barros, A. y Santaella, L. (Orgs.). Mídias e artes: os desafios da arte no início do século XXI. São Paulo: Unimarco, 2002. p. 60.

Fabbrini, R. (2001). "Arte e vida”. Folha de S. Paulo, Especial Jornal de Resenhas, 8 de setembro de 2001. p. 3.

Gil J. (2001). Movimento total: o corpo e a dança. Tradução Miguel Serras Pereira. Lisboa: Relógio d'Água.

. (1997). . Metamorfoses do corpo. Lisboa: Relógio d'Água.

Grau, O. (2005). “A história da telepresença: autômatos, ilusão e a rejeição do corpo". In: BENTES, Ivana. (Org.). Corpos virtuais. Rio de Janeiro: Centro Cultural Telemar, 2005. pp. 112-117.

Jeudy, H. (2002). O corpo como objeto de arte; tradução Tereza Lourenço. São Paulo: Estação Liberdade.

Junge, P. (2003). Arte da África: obras-primas do Museu Etnológico de Berlim. Rio de Janeiro: Centro Cultural Banco do Brasil.

Kehl, M. R. (2001). Orelha do livro "Corpos de passagem; ensaios sobre a subjetividade contemporânea” de Denise Bernuzzi de Sant’Anna. São Paulo: Estação Liberdade, 2001.

Labra D. (2006). “A arte processual em outra etapa. Número, n 9, dezembro de 2006. pp. 12-13.

Leiris, M. (1991). "Metamorphose - Hors de soi”, Documents n. 4, Paris: Jean Michel Plac. edição fac-similar.

Leite Brandao, C. A. (2003). “O corpo do Renascimento”. In: NOVAES, Adauto. (Org.). O homem-máquina: a ciência manipula o corpo. São Paulo: Companhia das Letras.

Lemos, A. (2002). Cibercultura, tecnologia e vida social na cultura contemporânea. Porto Alegre: Sulina.

Machado, A. (2001). O quarto iconoclasmo e outros ensaios hereges. Rio de Janeiro: Rios Ambiciosos.

Medeiros, M. (2003). A arte pesquisa, volume 2. História, teoria e crítica da arte. Brasília, D.F.: Mestrado em Artes, UnB.

Miranda, J. (1998). "Da interactividade: crítica da nova mímesis tecnológica". In: Gianetti, C. (Org.). Ars telemática: telecomunicação, internet e ciberespaço. Lisboa: Relógio d'Água.

Moraes, E. (2002). O corpo impossível. São Paulo: Iluminuras.

Name, D. (2004). “Corpo, memória e subjetividade nos anos 80". In: COSTA, Marcus de Lontra. Onde está você, Geração 80? Rio de Janeiro: CCBB, 2004. p. 15.

Oiticica, H. (2003). Cor, imagem, poética. Rio de Janeiro: Centro de Arte Hélio Oiticica.

Oliveros, R. (2004). "A moda como manifesto da arte". CULT - Revista Brasileira de Cultura, Ano VII, nº 82. São Paulo: Bregantini. Julho, 2004. pp. 56-60. 
Omar, A. (2005). “Afeganistão/Imagem/Memória. DERVIX versus MATRIX. A tecnologia é mental". In: BENTES, Ivana. (Org.). Corpos virtuais. Rio de Janeiro: Centro Cultural Telemar, 2005. pp. 17-23.

Santaella, L. y Noth, W. (2001). Imagem: cognição, semiótica, mídia. São Paulo: Iluminuras. Santana, D. (2001). Corpos de passagem; ensaios sobre a subjetividade contemporânea. São Paulo: Estação Liberdade.

Santos, J. (2006). Cybersenzala. São Paulo: Brasiliense.

Schilder, P. (1997). In: FERGUSON, Harvie. "Me and My Shadows: On the Accumulation of Body-Images in Western Society Part Two - The Corporeal Forms of Modernity. In: Body \& Society. v. 3, n. 4. Pp. 01-29.

Slater, D. (1998). "Trading sexpics on IRC; embodiment and authenticity on the Internet". In: Body \& Society, v. 4, n. 4. London: Sage Publications.

Thevoz, M (1984). Le corps peint: les illusions de la réalité. Genève: Skira.

Resumen: Se busca enfatizar, en el artículo, la complejidad de la cuestión del cuerpo, su elección y redefinición en el campo de las artes y sus límites. El desarrollo del biopoder con los estudios genéticos, la apología del metacorpo protético o del cuerpo virtual tal vez remiten al deseo de superación de la fragilidad de la carne y de la finitud. Son principalmente eventos artísticos contemporáneos que cuestionarán las normas de proxemia y comportamiento corporal, estimular nuevos contactos, nuevas actitudes y una nueva libertad, de inspiración natural, salvaje, infantil o tecnológica, enfatizando la interacción y el cuestionamiento de control.

Palabras clave: Cuerpo - Arte - Medios de comunicación - Biopoder - Comunicación Simulación.

Abstract: We emphasize, in the article, the complexity of the question of the body, its choice and redefinition in the field of the arts and its limits. The development of biopower with genetic studies, the apologia of the prosthetic metacorp or the virtual body may also refer to the desire to overcome the fragility of the flesh and of finitude. It is, above all, contemporary artistic manifestations that will question and dynamize the rules of proxemia and corporal behavior, stimulate new contacts, new postures and a new freedom, of natural, wild, infantile or even technological inspiration, emphasizing the interaction and questioning the control.

Keywords: Body - Art - Media - Biopower - Communication - Simulation.

[Las traducciones de los abstracts fueron supervisadas por el autor de cada artículo] 